\title{
Interaction Between CeramicPowder and Molten Calcia-Magnesia-Alumino-Silicate \\ (CMAS) Glass, and Its Implication on CMAS-Resistant Thermal Barrier Coatings
}

\author{
Amanda R. Krause, Xing $\mathrm{Li}^{\S}$, and Nitin P. Padture* \\ School of Engineering,Brown University, Providence RI, 02912, USA
}

For: Scripta Materialia

\begin{abstract}
Calcia-magnesia-alumino-silicate (CMAS)-attack mitigation mechanisms of $2 \mathrm{ZrO}_{2} \cdot \mathrm{Y}_{2} \mathrm{O}_{3}$ composition $\mathrm{TBCsare}$ investigated through a 'model' study where $2 \mathrm{ZrO}_{2} \cdot \mathrm{Y}_{2} \mathrm{O}_{3}$ ceramic powders are immersed in molten CMAS glass for various durations at 1300 ${ }^{\circ} \mathrm{C}$. The key insight gained from this study is that the formation of the CMAS-blocking apatite phase requires high concentration of $\mathrm{Y}^{3+}$ within a confined volume of CMAS, whereas the presence of a large-volume CMAS sink for $\mathrm{Y}^{3+}$ precludes the formation of apatite. It is alsodemonstrated that the ceramic microstructure has a profound effect on itsdissolution and penetration by CMAS, and on the concomitant crystallization of apatite.

$\S$ On leave from Beijing Institute of Technology, Beijing, 100081, P.R. China

*Author to whom correspondence should be addressed. Email: nitin_padture@brown.edu


Thermal barrier coatings (TBCs) made of the typical 7wt.\% $\mathrm{Y}_{2} \mathrm{O}_{3}$-stabilized $\mathrm{ZrO}_{2}$ (7YSZ) compositionarecommonly used to insulate and protect hot-section metallic components in gasturbine engines used for aircraft propulsion and electricity generation.[1-4]While TBCs allow higheroperatingtemperatures in enginesfor improved performance and efficiency, the rising engine temperatures introduce new materials requirements.[3, 4]For example, calcia-magnesiaalumino-silicates (CMASs) entering engines in the form of sand, fly ash, volcanic ash, runway debris, etc. melt at temperatures greater than $\sim 1200^{\circ}$ Cand damage the TBCs causing them to spall.[5-12]The molten CMAS glass infiltrates pores/cracksin the TBCs and dissolves the 7YSZ grains.[13]Reprecipitation of Y-depleted $\mathrm{ZrO}_{2}$ grainsoccurs due to the low solubility of $\mathrm{Zr}^{4+}$ in the CMAS glass compared with $\mathrm{Y}^{3+}$, consequently enriching the CMAS in $\mathrm{Y}^{3+} \cdot[12-16]$ However, the small amount of $\mathrm{Y}^{3+}$ solute available in $7 \mathrm{YSZ}$ TBCs $(0.08: 1:: \mathrm{Y}: \mathrm{Zr}$ atomic ratio) is not sufficient to alter thecomposition of the CMAS and its flow behavior significantly, resulting in full TBC penetration by the CMAS. Thus, conventional 7YSZ composition is ill-suited for TBC application at higher temperatures when CMAS is present.In this context, we recently showed thatby increasing the $\mathrm{Y}^{3+}$ solute content in $\mathrm{YSZ}$ TBCs $-2 \mathrm{ZrO}_{2} \cdot \mathrm{Y}_{2} \mathrm{O}_{3}(1: 1:: \mathrm{Y}: \mathrm{Zr}$ atomic ratio $)$ — the CMAS penetration is arrested at high temperature $\left(1340{ }^{\circ} \mathrm{C}\right) \cdot[17,18]$ This is attributed to the introduction of a sufficient amount of $\mathrm{Y}^{3+}$ into the CMAS during the dissolutionreprecipitation process, which inducescrystallization of an apatite phase from the CMAS and the reprecipitation of $\mathrm{Y}^{3+}$-lean $\mathrm{ZrO}_{2}$ grains.[18-20] The refractory apatite phase essentially 'seals' the coating, blocking further penetration of the CMAS.[18-20]TBCs made of other ceramics, such as rare-earth $(\mathrm{RE})$ zirconates $\left(\mathrm{RE}_{2} \mathrm{Zr}_{2} \mathrm{O}_{7}\right)$, also induce precipitation of apatite and other secondary phases during CMAS-mitigation.[9, 10, 13, 19, 21-23] While this effect is dramatic and it is of practical use, there are gaps in our understanding of the basic mechanisms involved. In 
found to be the 'solubility' limit of $2 \mathrm{ZrO}_{2} \cdot \mathrm{Y}_{2} \mathrm{O}_{3}$ powder in CMAS glass heat-treated at $1300{ }^{\circ} \mathrm{C}$ for 24 h.) The Pt crucibles with the sampleswere cut in half using a diamond saw, mounted in epoxy, and the cross-sectionswere polished to $1 \mu \mathrm{m}$ finish using standard metallographic techniques.

The cross-sectionswere characterized using a scanning electron microscope (SEM; LEO 1530VP, CarlZeiss, Germany) equipped with an energy dispersive spectrometer (EDS; Inca,Oxford Instruments, UK) and a transmission electron microscope (TEM;2100F, JEOL, Japan or CM20, FEI, Hillsboro, OR), operated at $200 \mathrm{kV}$ accelerating voltage, andalso equipped with EDS. The TEM specimen was obtained using focused ion beam (FIB; Helios 600, FEI, Hillsboro, OR). Electron probe micro-analysis (EPMA;Cameca SX-100, Cameca Instruments Inc., France), operatedwith a wavelength dispersive spectrometer (WDS) in conjunction with elemental standards, was used to measure the local chemical compositions of the CMAS and the grains more accurately.

In separate experiments, the solubility limit of $\mathrm{Y}^{3+}$ in the CMAS glass was determined by heat-treating several batches of $\mathrm{Y}_{2} \mathrm{O}_{3}$ powderand CMAS glass frit mixture, with increasing $\mathrm{Y}_{2} \mathrm{O}_{3}$ :CMAS ratios, at $1300{ }^{\circ} \mathrm{C}$ for $24 \mathrm{~h}$ in air, followed by quenching. The resulting materials were crushed and analyzed using X-ray diffraction (XRD; D8 Advance, Bruker AXS, Germany). The mixture in which the first appearance of discernible $\mathrm{Y}_{2} \mathrm{O}_{3}$ and/or apatite peaks above the amorphous hump was identified as the solubility limit. Similar experiments were performed using 7YSZ powder to determine the solubility limit of $\mathrm{Zr}^{4+}$.

Figure 1Ais a SEM micrograph of the starting $2 \mathrm{ZrO}_{2} \cdot \mathrm{Y}_{2} \mathrm{O}_{3}$ powder showing a combination of densified and partially-densified spheres (some hollow). Also, note the wide porosity and size 
distribution. Fortuitously, this diversity in the morphology and size allows us to study a rich variety of effects in a few experiments.

Figures $1 \mathrm{~B}$ and $1 \mathrm{C}$ are cross-sectional SEM micrographs showing interactions between $2 \mathrm{ZrO}_{2} \cdot \mathrm{Y}_{2} \mathrm{O}_{3}$ powderand CMAS glass heat-treated at $1300{ }^{\circ} \mathrm{C}$ for $1 \mathrm{~h}$. Figure $1 \mathrm{~B}$ shows the overall view where the powder particles are in a cluster and are starting to settle in the CMAS glass (dark gray) under gravity. Figure $1 \mathrm{C}$ is a higher-magnification SEM image of a region in the middle of the particle cluster showing different particle morphologies. One particle type, e.g.P1 in Fig. 1C (light gray), shows limited interactionwith little to no CMAS glass infiltration into the particle and a composition very similar to that of the original powder (e.g. Z1 in Fig. 1C and Table1). The faceted rod-like crystals (e.g. A1 in Fig. 1C) at the surface of these particles are apatite (medium gray), as identified by thechemical composition (Table 1). Other smaller, partially-densified particles,e.g. P2 in Fig. 1C, show evidence of extensive interaction with the CMAS glass. The initial particle morphology is no longer recognizable, and there is extensive formation of apatite.Some particles, e.g. P3 in Fig. 1C, show a mixed behavior, where the periphery has interacted with the CMAS glass extensively and is Y-depleted (composition Z2 in Table 1), with concomitant formation of apatite, while the interior is intact with no change in composition. A TEM specimen was extracted from the region specified (dashed rectangle) in Fig. $1 \mathrm{c}$ to investigate further the interactions between $2 \mathrm{ZrO}_{2} \cdot \mathrm{Y}_{2} \mathrm{O}_{3}$ particles and CMAS glass.

Figure $2 \mathrm{~A}$ is a bright-field TEM micrograph showing the CMAS attack front (dashed curve), which appears to be relatively evenwith no significant penetration into the grain boundaries of the interior of the grain. In the interaction region there are several examples of faceted apatite grains surrounded by $\mathrm{Y}$-lean, roundedc- $\mathrm{ZrO}_{2}$ grains (Figs. 2B and 2C). The elemental compositions of the grains A2 and Z4 are given in Table 1. The indexed selected area 
electron diffraction patterns (SAEDPs) in Fig. $2 \mathrm{C}$ confirm the phases A3 and Z3, to be apatite and $c-\mathrm{ZrO}_{2}$, respectively, and theirchemical compositions are given in Table 1.

The extent of the reaction with a particle, or the particle's morphology as observed in Fig. 1C, is depends on its initial surface area. Small, porous particles have sufficient surface area for rapid dissolution, inducing the precipitation of rounded, $\mathrm{Y}$-depleted $c-\mathrm{ZrO}_{2}$ grains and faceted apatite grains. Large particle with a dense exterior have a planar interface, in part due to the lack of grain boundary penetration, as observed in Fig. 2B. Therefore, the dissolution rate is controlled by the transport to and from the interaction interface. From these observations two important implications on TBCs can be derived. First, in air plasma sprayed (APS) TBCs, the adhesion and bonding of splat boundaries may play an important role in the CMAS-penetration behavior. Second, microstructure features influence the dissolution rate. This suggests that an optimum microstructure will need to be designed that willallow sufficient dissolution in the CMAS glass to allow apatite formation, but prevent significant CMAS penetration.

Previously, the apatite composition has been used to access CMAS mitigation capability.[19]The general formula for silicate-apatite is $\mathrm{A}_{4}{ }^{\mathrm{I}} \mathrm{A}_{6}{ }^{\mathrm{II}}\left(\mathrm{SiO}_{4}\right)_{6} \mathrm{O}_{x}[24]$, where the largerCa ${ }^{2+}$ occupies the larger $\mathrm{A}^{\mathrm{I}}$ site (coordination $(\mathrm{CN}) \# 9$ ), and the smaller $\mathrm{Y}^{3+}$ occupies the smaller $\mathrm{A}^{\mathrm{II}}$ site $(\mathrm{CN \#} 7)$ but it can also occupy the $\mathrm{A}^{\mathrm{I}}$ site. The oxygen content, $x$, is dependent on the cumulative valency of the cations; $x=2$ when all oxygen sites are occupied.[2426] Theoretically, the composition of silicate-apatite can range between $\mathrm{Ca}_{2} \mathrm{Y}_{8}\left(\mathrm{SiO}_{4}\right)_{6} \mathrm{O}_{2}$ and $\mathrm{Ca}_{4} \mathrm{Y}_{6}\left(\mathrm{SiO}_{4}\right)_{6} \mathrm{O}$ (listed in Table 1)[27]. The latter composition is thought to be less stable due to the high concentration of $\mathrm{O}^{2-}$ vacancies needed, but in this study the composition of apatite grains is closer to $\mathrm{Ca}_{4} \mathrm{Y}_{6}\left(\mathrm{SiO}_{4}\right)_{6} \mathrm{O}$. It is also noted that the apatite grains contain $\mathrm{Zr}^{4+}$ (Table 1), presumably in solid solution, which has also been observed in Gd-based silicate apatite[22]. It is 
suggested that $\mathrm{Zr}^{4+}$ may substitute for $\mathrm{Ca}^{2+}$ and/or $\mathrm{Y}^{3+}$, and will reduce the $\mathrm{O}^{2-}$ vacancy concentration by virtue of its higher valency.

An interesting observation in the overall view in Fig. $3 \mathrm{~A}$ is that the particles at the periphery of the cluster have dramatically different morphologies relative to the particles in the interior. More importantly, there is a big difference in the morphology of the side of individual particles facing the open CMAS glass and the side facingthe cluster, as seen in Figs. 3B and 3C. The CMAS-side is heavily infiltrated with extensive exfoliation, and dissolution/reprecipitation of Y-depleted $c-\mathrm{ZrO}_{2}$ grains (see composition of $\mathrm{Z} 5$ in Table 1). However, there is little evidence of apatite growth in that region. In contrast, there is no significant dissolution/exfoliation on the cluster-side of the $2 \mathrm{ZrO}_{2} \cdot \mathrm{Y}_{2} \mathrm{O}_{3}$ particles (see $\mathrm{Z6}$ in Table 1), but faceted apatite grains (medium gray) are found in the regions between particles, away from the periphery.Figure $3 \mathrm{D}$ plots the WDS elemental composition ( $\mathrm{Si}, \mathrm{Y}, \mathrm{Zr}$ ) of the CMAS glass as a function of distance away from the edge (bottom) of the particle cluster. The dashed lines in Fig. 3D indicate the measured CMAS glass composition (WDS)in the interior of the particle cluster. These data indicate that $\mathrm{Zr}^{4+}$ has a lower solubility in the CMAS glass compared with $\mathrm{Y}^{3+}$. Quantitatively, these resultsare also consistent with the independentlydetermined solubility limit of $\mathrm{Y}^{3+}$ and $\mathrm{Zr}^{4+}$ in the CMAS glass of $\sim 6$ at. $\%$ and $\sim 3$ at. $\%$ (cation basis), respectively, under the same heat-treatment conditions. The most striking feature of these data is that the $\mathrm{Zr}^{4+}$ concentration is homogenous in the CMAS, whereas the $\mathrm{Y}^{3+}$ concentration shows a significant concentration gradient. These observationsindicate thatconfinement of $\mathrm{Y}^{3+}$ in the CMAS melt plays a key role in apatite formation, which has important implications forthe CMAS-resistance in actual TBCs. In other words, large glass pockets, which could serve as large sinks for $\mathrm{Y}^{3+}$, are not desirable for the formation of CMAS-blocking apatite phase in TBCs. 
The following explanation forthis behavior is proposed. When a $2 \mathrm{ZrO}_{2} \cdot \mathrm{Y}_{2} \mathrm{O}_{3}$ grain dissolves in the CMAS glass, locally the glass is saturated in $\mathrm{Y}^{3+}$ and $\mathrm{Zr}^{4+}$. Since solubility of $\mathrm{Zr}^{4+}$ in the CMAS glass is about half of that for $\mathrm{Y}^{3+}, \mathrm{Y}$-depleted $c-\mathrm{ZrO}_{2}$ will nucleate heterogeneouslyand grow. The Y-content in the $c-\mathrm{ZrO}_{2}$ is likely to depend on various factors such as the partition (distribution) coefficient, which is not known for this system, and the amount of $\mathrm{Y}^{3+}$ available locally.For this system, the net gain of $\mathrm{Y}^{3+}$ in the glass is determined by the dissolution rate, transport of $\mathrm{Y}^{3+}$ to the glass sink, and its solubility limit. Apatite formation becomes favorable only when the Y-content exceeds $\sim 6$ at.\%. On the cluster-side, simultaneous dissolution of multiple particles introduces a high flux of $\mathrm{Y}^{3+}$ and $\mathrm{Zr}^{4+}$ into an effectively small volume of glass. The solubility limit of $\mathrm{Y}$ is exceeded due to the inefficiency of transport to the glass sink. Once again, the composition of the apatite will depend on the relative availability and activity of the necessary elements in the CMAS glass. On the periphery, apatite growth is suppressed due to insufficient amount of $\mathrm{Y}^{3+}$ in the glass, resulting from the transport of $\mathrm{Y}^{3+}$ into the large glass sink. Thus, CMAS glass can continue to penetrate the CMAS-side of the particles but not the cluster-side, as seen in Figs. 3A-3C.

A similar effect is observed in Fig. 4A in samples heat-treated for a longer duration $(4 \mathrm{~h}$ at $1300{ }^{\circ} \mathrm{C}$ ). The CMAS-side region $\mathrm{Z} 7$ is $\mathrm{Y}$-depleted with no evidence of apatite crystallization, whereas on the cluster-side apatite is observed and the region Z8 is not Y-depleted. Similarly, in the middle of the particles cluster, porous $2 \mathrm{ZrO}_{2} \cdot \mathrm{Y}_{2} \mathrm{O}_{3}$ particles are completely penetrated by CMAS with extensive apatite crystallization (e.g. P4 in Fig. 4B), while dense particles are only partially penetrated by CMAS, with some evidence of apatite crystallization. After $24 \mathrm{~h}$ heattreatment at $1300{ }^{\circ} \mathrm{C}$ most of the particles, and all of the apatite crystals, have dissolved in the CMAS glass (Figs 4C and 4D). Only remnants of Y-depleted $c-\mathrm{ZrO}_{2}$ grains are found settled to 
the bottom of the Pt crucible (e.g. Z9 in Fig. 4D and Table 1). The 24-h heat-treatment duration is sufficient for the $\mathrm{Y}^{3+}$ in the CMAS-glass to dissipate throughout, with total $\mathrm{Y}^{3+}$ contentin the CMAS glass well below the solubility limit.

The lack of apatite phase after 24-h heat-treatment exemplifies the transient nature of the TBC/CMAS interaction, and it is important to recognize that the precipitates may be metastable and their compositions can alter with time. In this context, Mechnich et al.[22]provided evidence for a change in the Gd-apatite composition with time in a $\mathrm{Gd}_{2} \mathrm{Zr}_{2} \mathrm{O}_{7} / \mathrm{CMAS}$ interaction study. A change in the apatite and $\mathrm{Y}$-depleted $c-\mathrm{ZrO}_{2}$ compositions with time has also been observed in an interaction study of $2 \mathrm{ZrO}_{2} \cdot \mathrm{Y}_{2} \mathrm{O}_{3}$ free-standing APS coatings with CMAS at $1340{ }^{\circ} \mathrm{C}$ (not published). Therefore, it is difficult to predict the CMAS-mitigating capability of a TBC ceramicjust based on the composition of the precipitates at a particular heat-treatment condition.

In closing, we have demonstrated the usefulness of model studies involving interactions between ceramic powders and CMAS glass in gaining insights into the CMAS-resistance of TBCs. The key insight gained in this study is that the formation of the desirable CMASblocking apatite phase requires high concentration of $\mathrm{Y}^{3+}$ within a confined volume (pocket) of CMAS glass, whereas the presence of a large-volume CMAS-glass sink for $\mathrm{Y}^{3+}$ precludes the formation of the apatite phase. In addition, it is shown that the ceramic microstructure has a profound effect on thedissolution and the penetration of the ceramic by the CMASglass. Ultimately, the relative rates of the dissolution and the transport of the relevant species will control the formation and the growth of the CMAS-attack-mitigating phases such as apatite. This understanding has far-reaching implications for the design of CMAS-resistant TBCs of the future. 
The support from the Office of Naval Research (grant no. N00014-15-1-2375, monitored by Dr. D. Shifler) is gratefully acknowledged. We thank Dr. H.F. Garces for experimental assistance. 
Table 1: Chemical compositions of grains and regions marked in

Figs.1,2, 3, and 4 and theoretical compositions of important apatite phases.

\begin{tabular}{|c|c|c|c|c|}
\hline At. \% Cation Basis & $\mathrm{Ca}$ & $\mathrm{Si}$ & $\mathrm{Y}$ & $\mathrm{Zr}$ \\
\hline $2 \mathrm{ZrO}_{2} \cdot \mathrm{Y}_{2} \mathrm{O}_{3}$ Powder $^{*}$ & - & - & 50.0 & 50.0 \\
\hline $\mathrm{Ca}_{4} \mathrm{Y}_{6}\left(\mathrm{SiO}_{4}\right)_{6} \mathrm{O}^{*}$ & 25.0 & 37.5 & 37.5 & - \\
\hline $\mathrm{Ca}_{2} \mathrm{Y}_{8}\left(\mathrm{SiO}_{4}\right)_{6} \mathrm{O}_{2}{ }^{*}$ & 12.5 & 37.5 & 50.0 & - \\
\hline $\mathrm{A}^{* *}$ & 19.3 & 36.6 & 38.4 & 5.7 \\
\hline $\mathrm{Z1}^{* *}$ & - & - & 47.1 & 52.9 \\
\hline $\mathrm{Z}^{* *}$ & 2.5 & 0.7 & 20.9 & 75.9 \\
\hline $\mathrm{A} 2$ & 15 & 40 & 41 & 4 \\
\hline $\mathrm{Z3}$ & 3 & - & 22 & 75 \\
\hline A3 & 17 & 39 & 40 & 4 \\
\hline$\overline{\mathrm{Z} 4}$ & 3 & - & 19 & 78 \\
\hline $\mathrm{Z5}$ & 4 & - & 18 & 77 \\
\hline $\mathrm{Z6}^{* *}$ & - & - & 52.3 & 47.7 \\
\hline $\mathrm{Z7}$ & 5 & 2 & 17 & 76 \\
\hline$\overline{Z 8}$ & - & - & 49 & 51 \\
\hline Z9 & 3 & - & 15 & 82 \\
\hline
\end{tabular}

*Idealcomposition

${ }^{* *}$ Measured using WDS. All others measured using EDS. 


\section{References}

[1] N.P. Padture, M. Gell, E.H. Jordan, Science 296 (2002) 280-284.

[2] A.G. Evans, D.R. Clarke, C.G. Levi, J. Eur. Ceram. Soc. 28 (2008) 1405-1419.

[3] D.R. Clarke, M. Oechsner, N.P. Padture, MRS Bull. 37 (2012) 891-898.

[4] R. Darolia, Intl. Mater. Rev. 58 (2013) 315-348.

[5] F.H. Stott, D.J. DeWet, R. Taylor, MRS Bull. 19 (1994) 46-49.

[6] J.L. Smialek, F.A. Archer, R.G. Garlick, JOM 46 (1994) 39-41.

[7] M.P. Borom, C.A. Johnson, L.A. Peluso, Surf. Coat. Technol. 86-87 (1996) 116-126.

[8] S. Krämer, S. Faulhaber, M. Chambers, D.R. Clarke, C.G. Levi, J.W. Hutchinson, A.G. Evans, Mater. Sci. Engr. A 490 (2008) 26-35.

[9] J.M. Drexler, A.D. Gledhill, K. Shinoda, A.L. Vasiliev, K.M. Reddy, S. Sampath, N.P. Padture, Adv. Mater. 23 (2011) 2419-2424.

[10] A.D. Gledhill, K.M. Reddy, J.M. Drexler, K. Shinoda, S. Sampath, N.P. Padture, Mater. Sci. Engr. A 528 (2011) 7214-7221.

[11] M.H. Vidal-Setif, N. Chellah, C. Rio, C. Sanchez, O. Lavigne, Surf. Coat. Technol. 208 (2012) 39-45.

[12] C.G. Levi, J.W. Hutchinson, M.-H. Vidal-Setif, C.A. Johnson, MRS Bull. 37 (2012) 932941.

[13] S. Krämer, J. Yang, C.G. Levi, C.A. Johnson, J. Am. Ceram. Soc. 89 (2006) 3167-3175.

[14] A. Aygun, A.L. Vasiliev, N.P. Padture, X. Ma, Acta Mater. 55 (2007) 6734-6745.

[15] M.H. Vidal-Setif, C. Rio, D. Boivin, O. Lavigne, Surf. Coat. Technol. 239 (2014) 41-48.

[16] H.F. Garces, B.S. Senturk, N.P. Padture, Scripta Mater. 76 (2014) 29-32. 
[17] A.R. Krause, B.S. Senturk, H.F. Garces, G. Dwivedi, A.L. Ortiz, S. Sampath, N.P. Padture, J. Am. Ceram. Soc. 97 (2014) 3943-3949.

[18] A.R. Krause, B.S. Senturk, N.P. Padture, J. Am. Ceram. Soc.97 (2014) 3950-3957.

[19] J.M. Drexler, A.L. Ortiz, N.P. Padture, Acta Mater. 60 (2012) 5437-5447.

[20] N.K. Eils, P. Mechnich, W. Braue, J. Am. Ceram. Soc.96 (2013) 3333-3340.

[21] U. Schulz, W. Braue, Surf. Coat. Technol. 235 (2013) 165-173.

[22] P. Mechnich, W. Braue, J. Am. Ceram. Soc.96 (2013) 1958-1965.

[23] D.L. Poerschke, C.G. Levi, J. Eur. Ceram. Soc.35 (2015) 681-691.

[24] J. Felsche. The Crystal Chemistry of the Rare-Earth Silicates. Structure and Bonding Volume 13. Berlin: Springer; 1973.

[25] J. Ito, Am. Min. 53 (1968) 890-907.

[26] R.D. Shannon, Acta Cryst. A 32 (1976) 751-767.

[27] T. Nagasawa, H. Yamane, S. Kubota, M. Shimada, J. Ceram. Soc. Jpn. 106 (1998) 12381241.

\section{Figure Captions}

1. (A) SEM image of the as-received $2 \mathrm{ZrO}_{2} \cdot \mathrm{Y}_{2} \mathrm{O}_{3}$ HOSP powder. Cross-sectional SEM images CMAS glass with the of the $2 \mathrm{ZrO}_{2} \cdot \mathrm{Y}_{2} \mathrm{O}_{3}$ in a Pt crucible heat-treated at $1300{ }^{\circ} \mathrm{C}$ for $1 \mathrm{~h}$ at: (B) low and (C) high magnifications, where the $2 \mathrm{ZrO}_{2} \cdot \mathrm{Y}_{2} \mathrm{O}_{3}$ HOSP powder is clustered near the surface of the CMAS glass. The dashed box indicates the region from where the TEM sample was extracted using FIB.

2. (A) Bright-field TEM images of the surface of particle P3 from Fig. 1C. The white dashed line indicates the CMAS-attack front. (B-C) Higher magnification TEM micrographs from the 
interaction regions in (a). Indexed SAEDPs of A3 and Z3 are included as insets in $(C)$, where ' $B$ ' indicates the zone axis and the transmitted beam is circled.

3.Cross-sectional SEM images of the sample from Fig. 1(B) $\left(1300{ }^{\circ} \mathrm{C}, 1 \mathrm{~h}\right)$ showing region near the particle-cluster periphery (denoted by the dashed curves): (A) at low magnification and (B)(C) at higher magnifications. (D) The elemental Si, Y, and $\mathrm{Zr}$ content in the glass, measured by WDS, as a function of distance from the particle-cluster edge. The dashed lines indicate the composition of the CMAS glass pockets within the interior of the particle-cluster.

4.Cross-sectional SEM images for sample heat-treated at $1300{ }^{\circ} \mathrm{C}$ for $4 \mathrm{~h}$ : (A) the particle-cluster periphery (dashed curve) region and (B) within the particle-cluster. Cross-sectional SEM images for sample heat-treated at $1300{ }^{\circ} \mathrm{C}$ for $24 \mathrm{~h}$ showing remaining ceramic particles at the bottom of the Pt crucible at: (C) low and (D) high magnifications. 

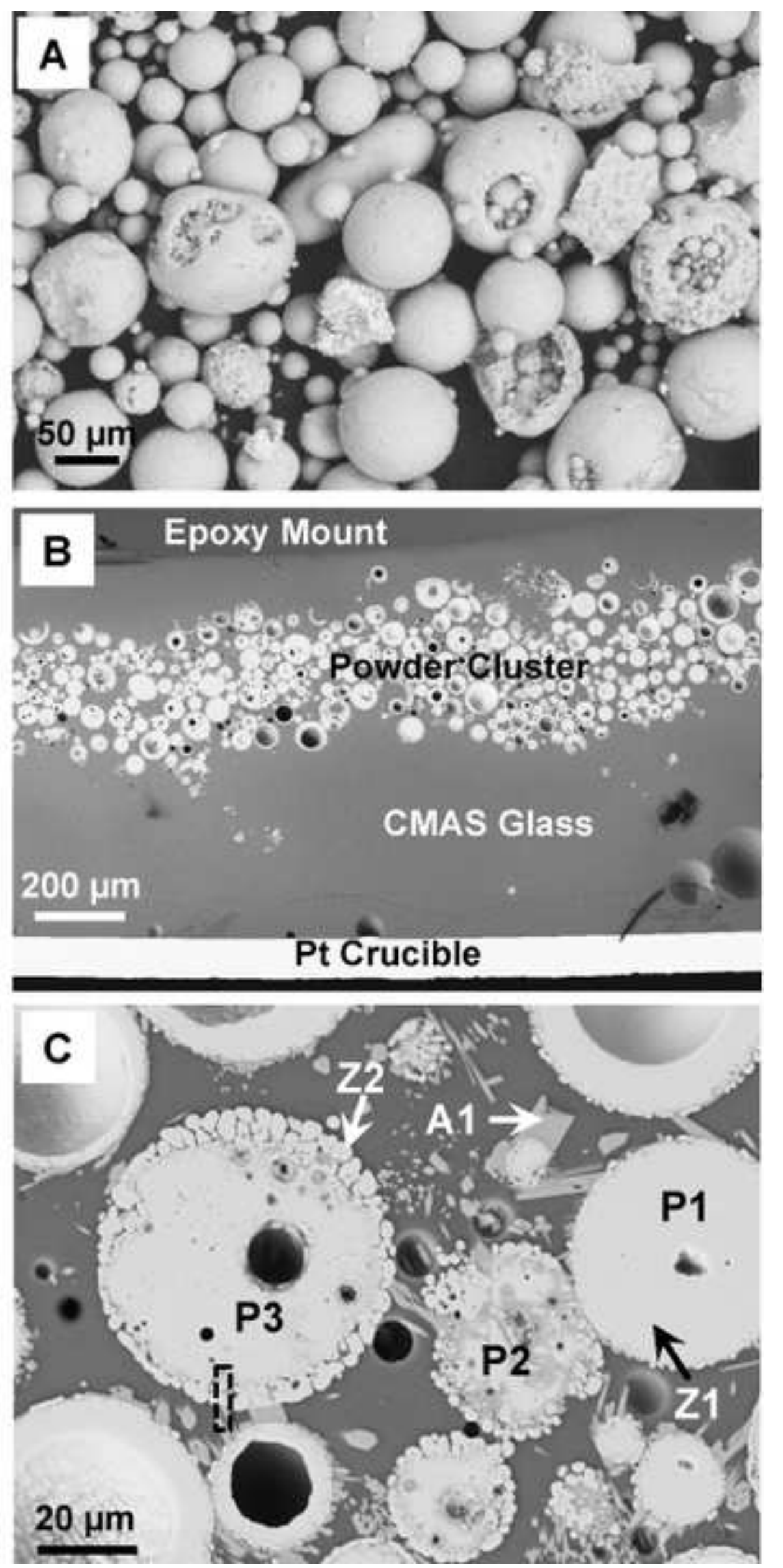

Figure(s)

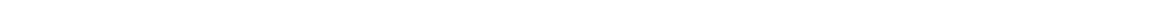

.

\title{
.
} .

\author{
.
}

$$
\text { . }
$$

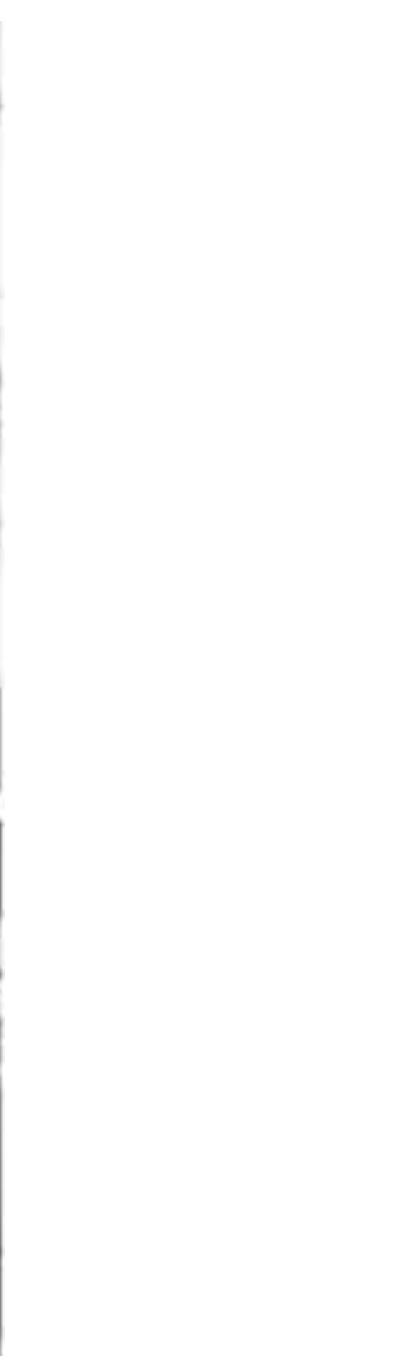

\section{.

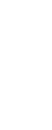

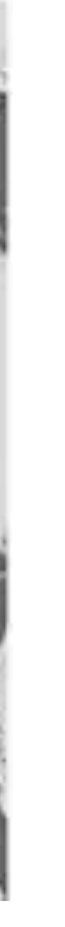

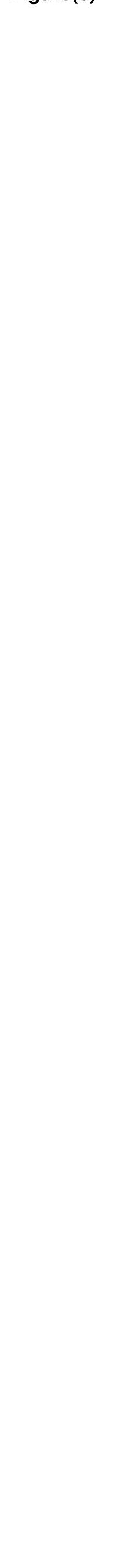




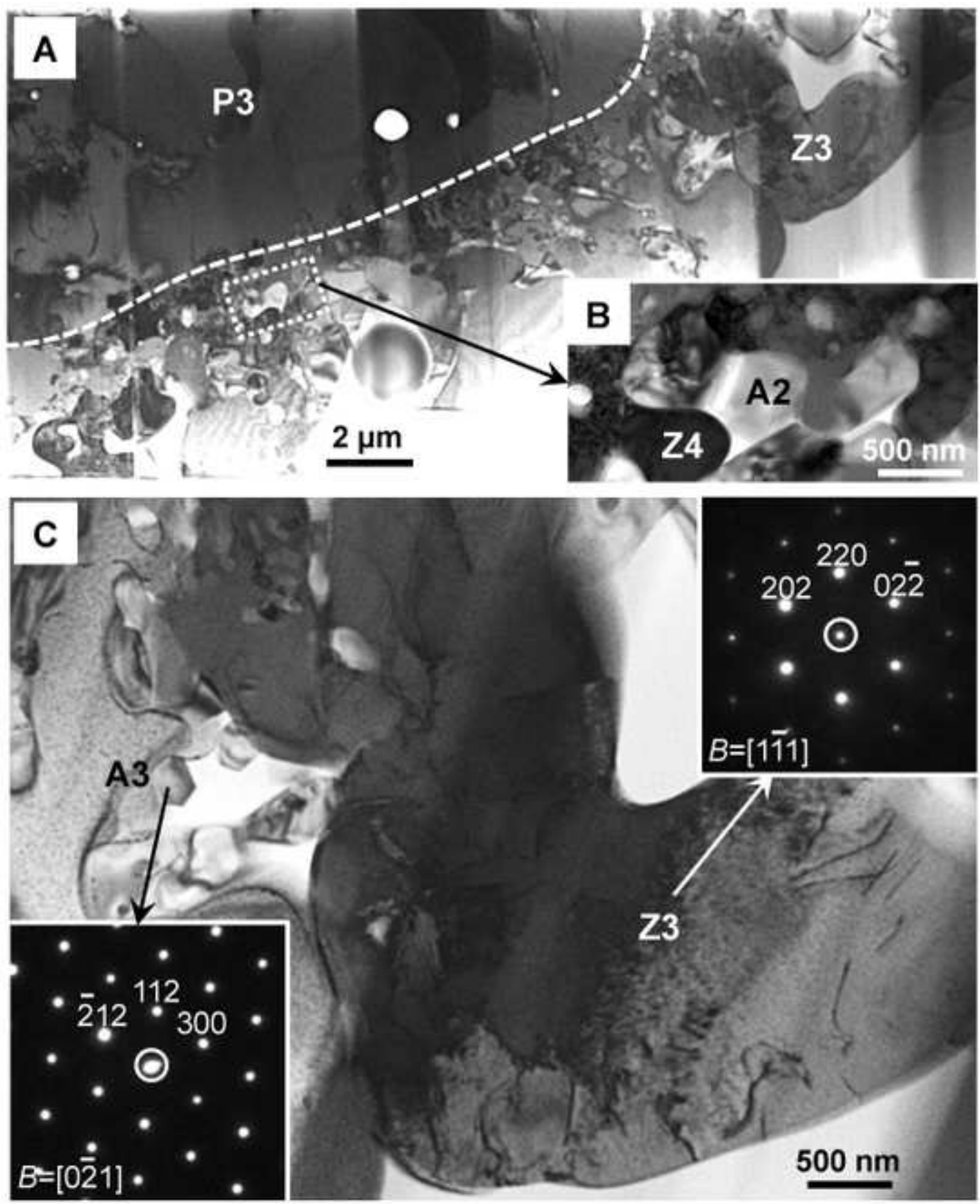



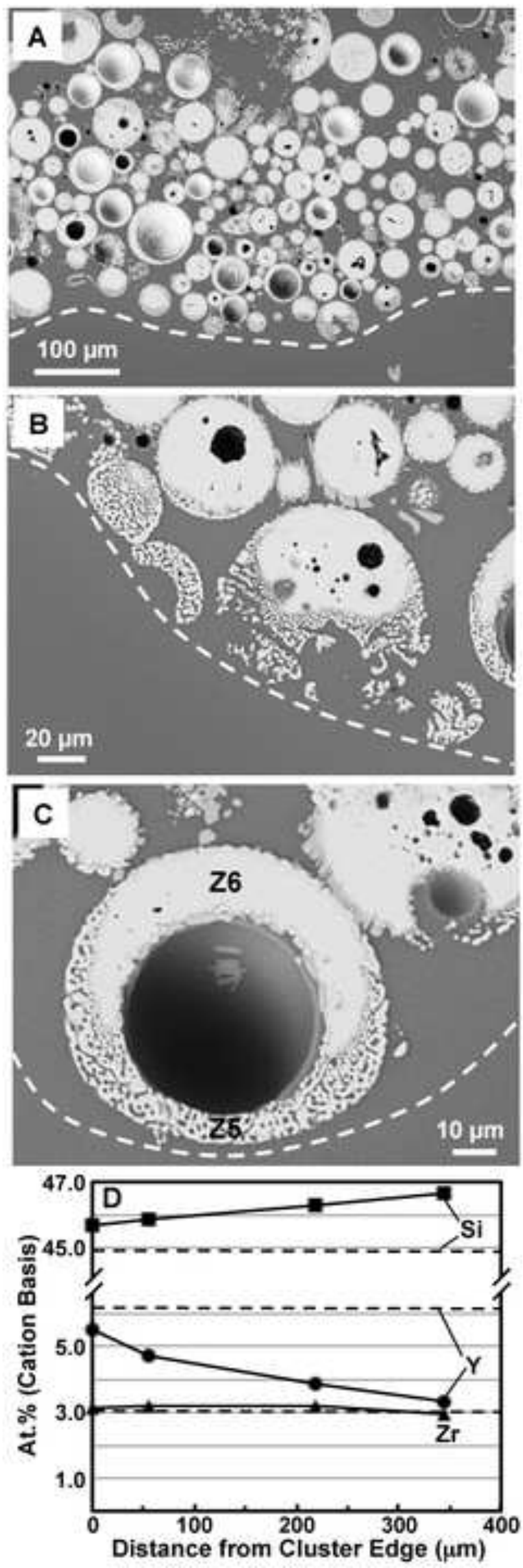

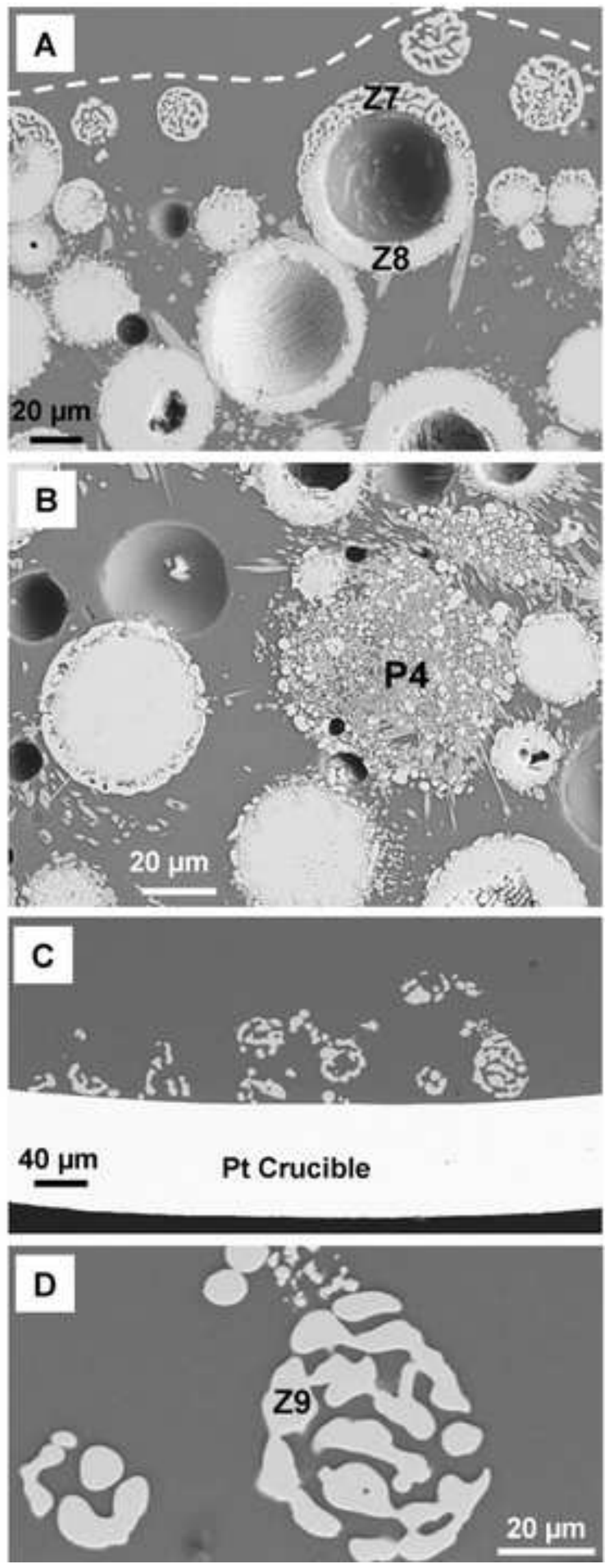


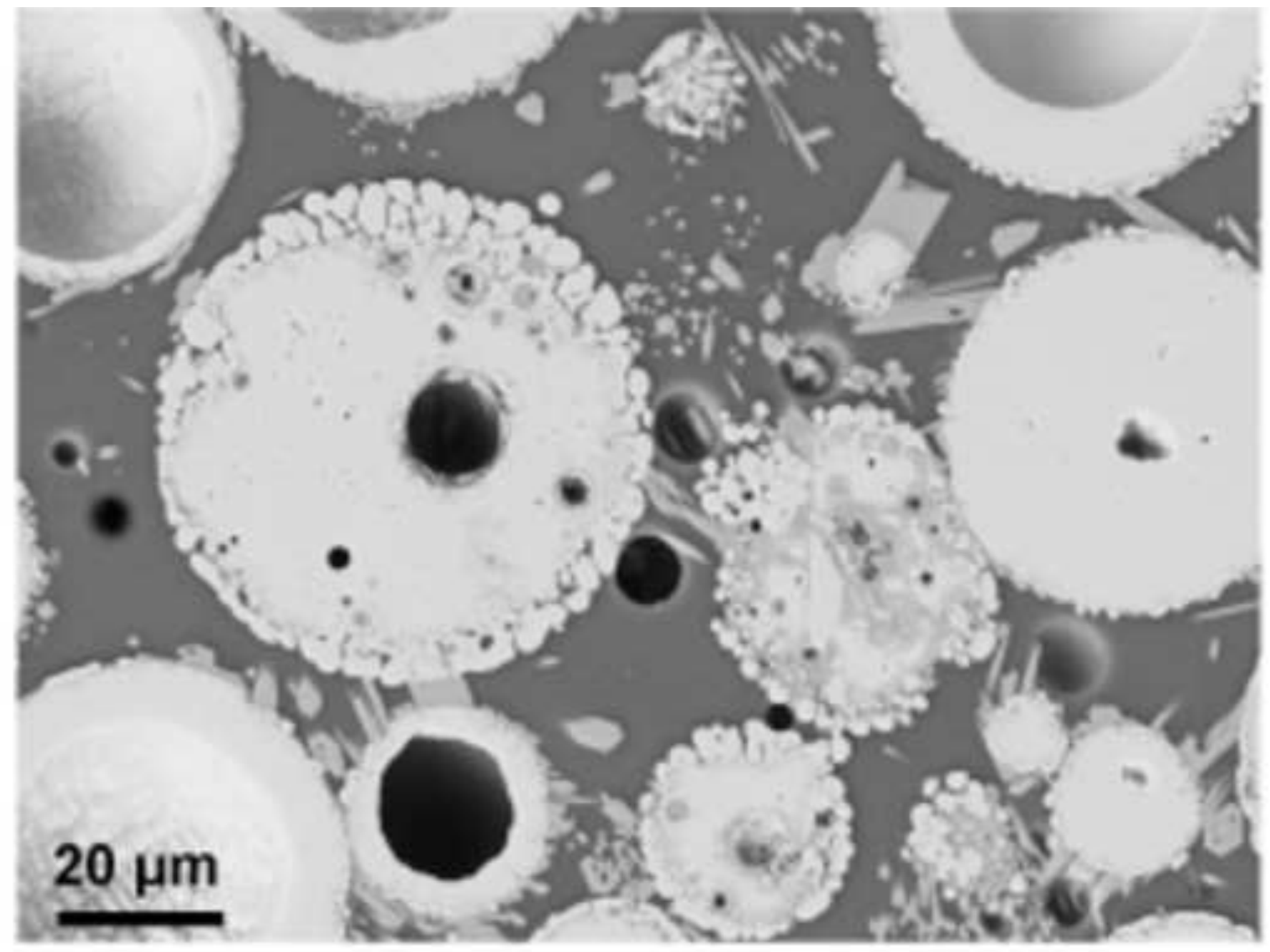

'Model' studies of high-temperature interaction between ceramic powder and calcia-magnesia-alumino-silicate (CMAS) glass for understanding mechanisms of CMAS-resistance in thermal barrier coatings. 